\title{
Dual Impact of Different Drying Treatments and Ethanol/Water Ratios on Antioxidant Properties and Colour Attribute of Jackfruit Leaves (Artocarpus heterophyllus Lam.) Mastura Variety (J35)
}

Haswani Maisarah Mustafa, ${ }^{a}$ Nor Amaiza Mohd Amin, ${ }^{\mathrm{a}, *}$ Rabitah Zakaria, ${ }^{\mathrm{a}}$ Mohd Shamsul Anuar, ${ }^{\mathrm{a}}$ Azhari Samsu Baharuddin, ${ }^{\mathrm{a}}$ Halimatun Saadiah Hafid, ${ }^{\mathrm{a}, \mathrm{b}}$ and Farah Nadia Omar ${ }^{\text {a }}$

\begin{abstract}
Artocarpus heterophyllus (jackfruit) leaves (JL) are a waste product that is commonly used as livestock feed. Jackfruit leaves have been revealed to possess many medicinal values such as antioxidant and antiinflammatory properties. In this study, different drying treatments (shade $(\mathrm{SD})$, sun (SN), and oven $(\mathrm{OV})$ ) and ethanol/water ratios (E/W) were investigated to evaluate the impact on drying kinetics, color, and antioxidant properties of jackfruit leaves. Results showed that the Newton model was the best fitted mathematical model for the JL drying kinetics. The moisture effective diffusivities ranged from $2.920 \times 10^{-10}$ to $6.814 \times 10^{-10} \mathrm{~m}^{2} / \mathrm{s}$ over the temperature range studied. Shade drying was able to preserve the green pigment better than OV and SN drying treatments. Treatment with ethanol/water ratio at $80 \%$ and oven-dried (OV80) revealed the highest phenolic content (195.05 $\pm 1.21 \mathrm{mg}$ gallic acid equivalent $(\mathrm{GAE}) / \mathrm{g}$ extract weight $(\mathrm{EW}))$, flavonoid content $(11.02 \pm$ $0.17 \mathrm{mg}$ artocarpin equivalent ( $\mathrm{AE}) / \mathrm{g} \mathrm{EW})$, and antioxidant activities (90\% scavenging activity and reducing power of $1043.84 \pm 5.28 \mu \mathrm{M}$ trolox equivalent (TE)/g EW) compared to SD and SN treatments. The OV80 also possessed the highest artocarpin, squalene, and $\beta$-sitosterol contents determined. The OV80 was selected for improving antioxidant and colour stability, and has the potential to be developed into functional biopolymer production.
\end{abstract}

Keywords: Artocarpus heterophyllus leaves; Drying; Newton model; Antioxidant; Aartocarpin

Contact information: a: Department of Process and Food Engineering, Faculty of Engineering, Universiti Putra Malaysia, 43400 UPM Serdang, Selangor; b: Graduate School of Life Science and System Engineering, Kyushu Institute of Technology, 2-4 Hibikino, Wakamatsu-ku, Kitakyushu, 808-0196, Japan;

*Corresponding author: myza@upm.edu.my

\section{INTRODUCTION}

Jackfruit, which is scientifically known as Artocarpus heterophyllus Lam., is a tropical fruit that is popular in Malaysia. Originated from India, it is widely cultivated in other countries such as Thailand, Vietnam, Indonesia, the Philippines, Sri Lanka, China, and Brazil (Zheng et al. 2014). Jackfruit has been reported to have both flesh and seeds customarily eaten, boiled, or fried; and the non-edible part, such as leaves, has been revealed to possess medicinal values such as antioxidant, anti-inflammatory, antimicrobial, anticancer, hypoglycemic, and hypolipidemic activities (Jagtap and Bapat 2010; Baliga et al. 2011). 
Jackfruit leaf extract was also reported to contain high antioxidant properties in the aqueous fraction $(294.5 \mathrm{mg} / \mathrm{g})$, ethyl acetate extract $(361.2 \mathrm{mg} / \mathrm{g})$, both of which exhibited high scavenging activities (219.9 and $235.8 \mu \mathrm{g} / \mathrm{mL}$, respectively) (Loizzo et al. 2010).

Upon detachment from the twigs after harvesting, jackfruit leaves may deteriorate, thus reducing their shelf life. Therefore, there is a need for preservation to be able to prolong their shelf life. Drying is a preservation method commonly applied to prevent microbial growth and reduce enzymatic activity, thus extending the shelf life of plant material at room temperature. However, during the drying process, deterioration and changes in properties lead to the undesirable impact on the quality of the product (Babu et al. 2018).

Changes in color, aroma, and degradation of bioactive compounds serve as an indicator of the oxidation process. Exposure to exhaustive long hours of drying time and high temperature could result in reduced antioxidant properties. Drying methods that are commonly used include convection drying, shade drying, and sun drying. Previous studies exposed jackfruit leaves to various drying methods, particularly to evaluate the effect of drying methods on the cellular constituent that can release the phenolic compound from the plant material (Roshanak et al. 2016). Prakash et al. (2017) reported on the shade-dried jackfruit leaves for wound healing properties, focusing on the excision model and phytochemical screening for the presence of flavonoids. Ojwang et al. (2017) reported that the air-dried drying method of jackfruit leaves still contain an amount of antioxidant activities (65\% to $78 \%)$.

The air-dried under the shade of jackfruit leaves collected from different districts in Uganda were also revealed to present an abundant amount of total phenolic content and total flavonoid content (ranging from 37.39 to $30.92 \mathrm{mg} / \mathrm{g}$ and 5.02 to $6.70 \mathrm{mg} / \mathrm{g}$, respectively).

For many years, different drying methods of leaves have been adopted to reach a compromise between quality and efficiency. Options included the commonly used method, the shade drying. Donkor et al. (2016) reported that natural drying may result in a slight decrease of flavonoid compound with the temperature increased. In contrast, a higher temperature $\left(60\right.$ to $\left.70{ }^{\circ} \mathrm{C}\right)$ leads to an increase in carvacrol content but causes darkening of the leaf color (Rahimmalek and Goli 2013; Roshanak et al. 2016). However, the leaf color may retain the color quality demonstrated by lowering drying temperature to $40{ }^{\circ} \mathrm{C}$ (Chua et al. 2019a).

Conventional drying process always suffers from a long drying time with high energy consumption. A co-drying technique with solvent was introduced to increase the drying rate with better process control without reducing the quality of bioactive compounds, colour, and antioxidant properties. Thus, it could lead to better nutrient preservation. To the best of the author's knowledge, there has been a lack of studies on the effect of drying characteristics and solvent ratios on the quality attributes of jackfruit (Artocarpus heterophyllus) leave extract. The aim of the present work is to determine the impact of shade, sun, oven treatments, and ethanol/water solvent ratios on colour and antioxidant properties of jackfruit (Artocarpus heterophyllus Lam. var. Mastura) (J35) leaves extract. 


\section{EXPERIMENTAL}

\section{Materials}

Fresh jackfruit leaves (Artocarpus heterophyllus Lam. var. Mastura) were harvested from a jackfruit plantation owned by Farmers' Organisation, Maran, Pahang Darul Makmur, Malaysia $\left(3.5829^{\circ} \mathrm{N}, 102.7748^{\circ} \mathrm{E}\right)$. The leaves were labelled as JL. Upon arrival, the leaves were washed with clean water to remove surface dirt and any debris. Then, it was packed in average weight of $500 \mathrm{~g}$ of $\mathrm{JL}$ in polyethylene bag prior to drying. Moisture content of the sample was measured using a digital moisture analyzer (MB45; Ohaus Corporation, Parsippany, NJ, USA) in triplicate. The leaves were weighed to $(2.0 \pm 0.01 \mathrm{~g})$ and heated at $103 \pm 0.1 \mathrm{~g}$ until a constant weight was achieved.

\section{Chemicals and reagents}

Ethanol was purchased from John Kollin Corporation (Midlothian, Scotland). Folin-Ciocalteu reagent, sodium carbonate $\left(\mathrm{Na}_{2} \mathrm{CO}_{3}\right)$, and ferric chloride hexahydrate $\left(\mathrm{FeCl}_{3} \cdot 6 \mathrm{H}_{2} \mathrm{O}\right)$ were purchased from Merck, Darmstadt, Germany. Chemicals of 2,4,6-tris2,4,6-tripyridyl-s-triazine (TPTZ), sodium acetate trihydrate, 1,1-diphenyl-2picrylhydrazyl (DPPH), and Trolox (6-hydroxy-2,5,7,8-tetramethylchromane-2carboxylic acid, 97\%) as well as 5- $\alpha$-cholestane, squalene, and $\beta$-sitosterol standards were purchased from Sigma Chemical Co. (St. Louis, MO, USA). Artocarpin standard was purchased from Chemfaces (Wuhan, China). Methanol used for high-performance liquid chromatography (HPLC) analysis was purchased from Merck (Darmstadt, Germany). All reagents used were of analytical grade unless otherwise stated.

\section{Methods}

\section{Drying of jackfruit leaves}

Shade drying: Jackfruit leaves were spread evenly on a net in a single layer under shade with average temperature and relative humidity of approximately $25{ }^{\circ} \mathrm{C}$ and $58 \%$, respectively. Samples were dried and the moisture content measurements were taken on an hourly basis until they reached constant moisture content. Moisture content was analyzed using the digital moisture analyzer.

Sun drying: Approximately $30 \mathrm{~g}$ of fresh JL were weighed in different batches. Every batch was evenly distributed and exposed to sunlight with average temperature readings and relative humidity of approximately $33{ }^{\circ} \mathrm{C}$ and $45 \%$, respectively. All samples were allowed to dry from 8:00 h to 18:00 $\mathrm{h}$ and collected in the evening, and the moisture content reading was taken on an hourly basis. Samples were immediately put in desiccator for 15 minutes before measuring the moisture content using the digital moisture analyzer in triplicate until constant weight was achieved in percentage (\%) unit.

Oven drying: Approximately $30 \mathrm{~g}$ of jackfruit leaves were dried at $40{ }^{\circ} \mathrm{C}$ using an automatic electric oven (Memmert $\mathrm{GmbH}+\mathrm{Co}$. KG, Büchenbach, Germany) in triplicate. The oven was pre-heated for 30 minutes to condition the temperature at $40{ }^{\circ} \mathrm{C}$. Then, the jackfruit leaves were evenly spread on the stainless steel grids to avoid stacking on each other to achieve maximum drying surface area. Moisture content of samples was checked using the digital moisture analyzer. 
Mathematical modeling of drying kinetics

Table 1 shows the mathematical models to describe the drying kinetics of jackfruit leaves for each method. The moisture ratios (MR) of JL were calculated using Eq. 1,

$$
M R=\frac{M_{t}-M_{e}}{M_{0}-M_{e}}
$$

where $M R$ is the moisture ratio, $M_{\mathrm{t}}$ is the moisture (\%) at time $t, M_{0}$ is the initial moisture $(\%)$, and $M_{\mathrm{e}}$ is the moisture at equilibrium (\%). Assuming the values of $M_{\mathrm{e}}$ equal to zero are negligible, due to $M_{\mathrm{e}}$ being relatively small compared to $M_{\mathrm{t}}$ or $M_{\mathrm{i}}$ (Doymaz and Kipcak 2018).

Problem solver Microsoft Excel (Microsoft Corp., v. 2010, Redmond, WA, USA) was used to solve the seven nonlinear mathematical models (Table 1). Chi square $\left(\chi^{2}\right)$ and root mean square error (RMSE) were used to evaluate the relationship of the experimental and predicted results in addition to the correlation coefficient $\left(\mathrm{R}^{2}\right)$. The following equations were employed to calculate $\chi^{2}$ and RMSE,

$$
\begin{aligned}
& \chi^{2}=\frac{\sum_{i=1}^{n}\left(M R_{i}-\overline{M R}\right)^{2}}{n-1} \\
& R M S E=\sqrt{\frac{\sum_{i=1}^{n}\left(M R_{\text {i experimental }}-M R_{i \text { calculated }}\right)^{2}}{n}}
\end{aligned}
$$

where $M R_{\mathrm{i}}$ experimental is the concentration of experiment $\mathrm{I}$, and $M R_{\mathrm{i}}$ calculated is obtained from the model equation, and $n$ represents the number of experiments.

Table 1. Mathematical Model Applied for Drying Curves

\begin{tabular}{|c|c|c|}
\hline No. & Model Name & Model Equation \\
\hline 1. & Newton & $M R=\exp (-\mathrm{k} t)$ \\
\hline 2. & Logarithmic & $M R=\mathrm{a} \exp (-\mathrm{k} t)+\mathrm{c}$ \\
\hline 3. & Verma & $M R=\mathrm{a} \exp (-\mathrm{k} t)+(1-\mathrm{a}) \exp (-\mathrm{g} t)$ \\
\hline 4. & Two term & $M R=\mathrm{a} \exp \left(-\mathrm{k}_{0} t\right)+\mathrm{b} \exp \left(-\mathrm{k}_{1} t\right)$ \\
\hline 5. & Midilli & $M R=\mathrm{a} \exp \left(-\mathrm{k} t^{\wedge} \mathrm{n}\right)+\mathrm{bt}$ \\
\hline 6. & Page & $M R=\exp \left(-\mathrm{k} t^{\wedge} \mathrm{n}\right)$ \\
\hline 7. & Henderson and Pabis & $M R=\mathrm{a} \exp (-\mathrm{k} t)$ \\
\hline
\end{tabular}

Determination of effective diffusivity

Drying characteristics of biological products can be described by Fick's law diffusion model as represented by Eq. 4,

$$
\ln (M R)=\left(\frac{6}{\pi^{2}}\right)-\left(\frac{D_{e f f}}{r^{2}}\right) x t
$$

where $D_{\text {eff }}$ is the effective diffusivity of moisture $\left(\mathrm{m}^{2} / \mathrm{s}\right), t$ is the time for drying (s), and $r$ is the radius of the plant $\left(r=7.8 \times 10^{-4} \mathrm{~m}\right)$. The form of Eq. 4 can be applied for particles with slab geometry assuming uniform initial moisture distribution. The diffusivity equation provides an approximate method to present a common quantitative comparison of various products in the aspect of the diffusion coefficient in the process of drying. 


\section{Color determination}

The dried leaves were crushed and ground to a fine powder using a hammer mill (Perten Laboratory Mill 120; Perten Instruments, Hägersten, Sweden). Evaluations of colour were tested on a colorimeter (Konica Minolta Color Reader CR10; Konica Minolta Sensing Americas, Inc., Ramsey, NJ, USA). Measurement of color was determined in $L^{*}, a^{*}$, and $\underline{b}^{*}$ coordinates, where $L$ is the lightness $(0=$ black, $100=$ white). The $L^{*}, a^{*}$, and $b^{*}$ values are the averages of three readings. The chromaticity coordinate $a^{*}$ measures red $(+)$ and green $(-)$, and the chromaticity coordinate $b^{*}$ measures yellow (+) and blue (-). The $L^{*}$ and $a^{*} / \underline{b}^{*}$ values are commonly used as an index to report the color quality.

\section{Extraction of jackfruit leaves}

Shade-dried (SD), sun-dried (SN), and oven-dried (OV) samples were extracted using the maceration method. The sample was dissolved in ethanol/water ratio of $1: 20$ with modification (Perva-Uzunalic et al. 2006) as described in Table 2. Samples were left in the incubator shaker for $3 \mathrm{~d}$ with continuous stirring at $200 \mathrm{rpm}$. Samples were filtered and the solvent was evaporated to dryness using a rotary evaporator to afford a thick green mass. All experiments in this study were performed in triplicate.

Table 2. Ranges of Experimental Variables

\begin{tabular}{|c|c|c|}
\hline Drying Method & Ethanol Percentage (\%) & Acronym \\
\hline \multirow{4}{*}{ Shade (SD) } & 100 & SD100 \\
\cline { 2 - 3 } & 80 & SD80 \\
\cline { 2 - 3 } & 50 & SD50 \\
\hline \multirow{3}{*}{ Sun (SN) } & 0 (Water only) & SD-W \\
\cline { 2 - 3 } & 100 & SN100 \\
\cline { 2 - 3 } & 80 & SN80 \\
\cline { 2 - 3 } & 50 & SN50 \\
\hline \multirow{3}{*}{ Oven at $40^{\circ} \mathrm{C}(\mathrm{OV})$} & 0 (Water only) & SN-W \\
\cline { 2 - 3 } & 100 & OV100 \\
\cline { 2 - 3 } & 80 & OV80 \\
\cline { 2 - 3 } & O (Water only) & OV50 \\
\hline
\end{tabular}

\section{Spectrophotometric Analysis}

Total phenolic content (TPC) and total flavonoid content (TFC)

Total phenolic content and total flavonoid content were analyzed spectrophotometrically (Shimadzu UV1800; Shimadzu Scientific Instruments, Columbia, MD, USA) as described by Mustafa et al. (2016). Gallic acid was prepared according to the Folin-Ciocalteu assay as standard solution, and the results were prepared with gallic acid as standard with calibration curve $(0.0,0.2,0.4,0.6,0.8$, and $1 \mathrm{mg} / \mathrm{mL})$ and expressed as gallic acid equivalent (mg GAE/g extract). Absorbance was read at $725 \mathrm{~nm}$ against ethanol as blank. The total flavonoid content was prepared with artocarpin as standard with the calibration curve $(0.0,0.2,0.4,0.6,0.8$, and $1 \mathrm{mg} / \mathrm{mL})$. The absorbance was measured spectrophotometrically at $513 \mathrm{~nm}$. Results were expressed as artocarpin equivalents (mg AE/ g extract). 


\section{Antioxidant activities}

The ferric reducing antioxidant power (FRAP) assay was performed according to the method described by Liu et al. (2009) with modifications of the adjusted volume of FRAP reagent. The FRAP reagent contained $20 \mathrm{mM} \mathrm{FeCl}_{3} \cdot 6 \mathrm{H}_{2} \mathrm{O}, 10 \mathrm{mM}$ TPTZ $(2,4,6-$ tripyridyl-s-triazine) solution in $40 \mathrm{mM} \mathrm{HCl}$, and $0.3 \mathrm{M}$ acetate buffer with $\mathrm{pH} 3.6$, and incubated at $37{ }^{\circ} \mathrm{C}$ for $10 \mathrm{~min}$ in an incubator (Memmert $\mathrm{GmbH}+\mathrm{Co} . \mathrm{KG}$, Schwabach, Germany). The FRAP reagent was mixed in the ratio of 1:1:10. Aliquot of $100 \mu \mathrm{L}$ sample was mixed with $2.9 \mathrm{~mL}$ of FRAP reagent. The absorbance was measured spectrophotometrically at $593 \mathrm{~nm}$ after incubation at room temperature for $1 \mathrm{~h}$. Trolox $(1000 \mu \mathrm{M})$ was used for the calibration curve, and the results were expressed as $\mu \mathrm{M}$ of Trolox equivalents per gram extract weight.

The antioxidant activity was carried out through evaluation of free radical scavenging effect on 1,1-diphenyl-2-picrylhydrazyl (DPPH). The determination was based on the method described by Yamaguchi et al. (1998) with some modification on sample volume added. An aliquot $(600 \mu \mathrm{L})$ sample was added to $4.5 \mathrm{~mL}$ of $0.1 \mathrm{mM}$ DPPH ethanolic solution. The mixture was then thoroughly vortexed and incubated for 20 min in dark conditions at room temperature. The absorbance was measured at $517 \mathrm{~nm}$ against ethanol as blank. Results were expressed as a percentage of inhibition of the DPPH radical and calculated according to Eq. 5,

$$
\% \text { inhibition of DPPH }=\frac{(\text { Abs control }- \text { Abs sample })}{\text { Abs control }} \times 100
$$

where Abs control is the absorbance measured as absorbance unit (AU) of DPPH without sample.

\section{Quantification of Compounds}

Bioactive compound by HPLC

The sample with the highest amount of antioxidant properties from each treatment was further analyzed for artocarpin content. Artocarpin in samples was analyzed using a Shimadzu HPLC system (Shimadzu SPD-10AV, Shimadzu Scientific Instruments, Columbia, MD, USA), which was equipped with a ultraviolet/visible (UV/VIS) detector (SPD-10AV) (i.d. $4.6 \times 250 \mathrm{~mm}, 5 \mu \mathrm{m}$ column). The analysis was performed according to Septama and Panichayupakaranant (2016) with modification of the adjusted mobile phase. A mobile phase was prepared that consisted of methanol and water (85\% methanol and $15 \%$ deionized water), at a flow rate of $1 \mathrm{~mL} / \mathrm{min}$. Detection of artocarpin using HPLC was coupled using a diode array detector (DAD) at $285 \mathrm{~nm}$. All volume samples were injected at $20 \mu \mathrm{L}$. The identification of the compound was based on the comparison with external standards. The signals and area of each peak were processed using Class VP software (Shimadzu LabSolutions, v.6.14, Kyoto, Japan). The amount of sample was expressed as milligram per gram of extract weight $(\mathrm{mg} / \mathrm{g})$.

\section{Volatile compounds by gas chromatography $(G C)$}

The sample with the highest amount of antioxidant properties from each treatment was further analyzed for volatile compounds. Samples were prepared by adapting the standard method Cd 11b-91 (Bruschweiler and Dieffenbacher 1991) using Shimadzu GC2010 Plus equipped with split/splitless injector and flame ionization detector (FID) (Shimadzu, Kyoto, Japan). Approximately, $0.02 \mathrm{~g}$ of the sample was weighed and added 
with 5- $\alpha$-cholestane serving as an internal standard (ISTD), $0.3 \mathrm{~mL}$ pyridine, and 0.15 $\mathrm{mL} \mathrm{N}$-trimethylsilyl-N-methyl-trifluoroacetamide (MSTFA). The sample solution was mixed well and heated at $40{ }^{\circ} \mathrm{C}$ for silylation purposes. The $\mathrm{GC}$ analysis was performed using a capillary column, HT5 $(12 \mathrm{~m} \times 0.32 \mathrm{~mm}$, i.d. $0.1 \mathrm{~m}$, Scientific Glass Engineering Analytical Science (SGE), Melbourne, Australia). The temperatures of the flame ionization detector (FID) and injector were set at $370{ }^{\circ} \mathrm{C}$ and $360{ }^{\circ} \mathrm{C}$, respectively. The oven was set initially at $80{ }^{\circ} \mathrm{C}$, held for $1 \mathrm{~min}$, and then increased from $10{ }^{\circ} \mathrm{C} / \mathrm{min}$ to 360 ${ }^{\circ} \mathrm{C} / \mathrm{min}$, followed by maintaining at $360{ }^{\circ} \mathrm{C}$ for $15 \mathrm{~min}$. Hydrogen was used as a carrier gas at a flow rate of $30 \mathrm{~mL} / \mathrm{min}$. For the GC analysis, a split ratio of 1:10 was set, and a 1 $\mu \mathrm{L}$ of sample solution was injected into the GC system.

\section{Statistical analysis}

All experiments were performed in triplicate, and the results were given as means \pm standard deviation. Differences among the treatments were determined using an analysis of variance (ANOVA) and a Tukey test with a confidence level of $\mathrm{P}<0.05$ to indicate significant differences. The analyses were made using Minitab 16 software (Minitab Inc., State College, PA, USA).

\section{RESULTS AND DISCUSSIONS}

\section{Impact of Drying Treatments}

Heat-treated jackfruit leaves resulted in losses in moisture content under shade, sun, and oven, as depicted in Fig. 1. The initial moisture content of jackfruit leaves was 60.4 to $62.7 \%$. The drying time for sun treatment was 5.4 times and 1.6 times faster than shade and oven conditions, respectively. The reduced drying time distributed by the external parameters that may affect the drying process include wind speed, humidity, temperature, air stream velocity, heat supply, the contact between hot surfaces and the wet solid, and solar radiation (Sodha et al. 1985; Jain and Tiwari 2003; Prasad 2009). In addition, open space under sun drying allowed higher diffusion coefficient of product per unit exposed area while oven treatment had a slower drying rate due to lower diffusion coefficient of the oven resulting in an increase of relative humidity in the oven chamber (Kumar and Tiwari 2007; Arslan and Özcan 2010). The highest temperature that was recorded during sun drying the sample was approximately $38{ }^{\circ} \mathrm{C}$ during mid-day. The heat penetrates inside the sample, producing a moisture gradient in the sample, and water vapor starts to form. Diffusion of moisture and water vapor takes place from the interior replacing the loss of moisture by evaporation on the surface. Higher drying rates occur in the beginning and become gradually reduced through the end of drying process. Similar results have been obtained by other researchers in relation to other fruits and vegetables (Alara et al. 2018; Tellez et al. 2018). Although the sun drying method showed the shortest time compared to shade and oven methods due to fluctuating sunlight, the drawbacks of this treatment are the unhygienic conditions, such as dust particles, microbial attack, prone to damage, and loss to nutritional attributes, at the peak of daytime. Whilst shade drying is able to prevent damage and loss of compound of interest, the drawback of this shade treatment is that it requires the longest time to achieve its constant weight. Furthermore, natural drying treatments (shade and sun drying) are also 
unable to achieve consistent quality standards (Roshanak et al. 2016; Babu et al. 2018). Despite many drawbacks highlighted for natural drying treatments, these methods are accessible and free source. Although oven drying was operated at a cost estimated at USD 80, this method is preferable as it is more efficient in terms of producing optimum quality product.

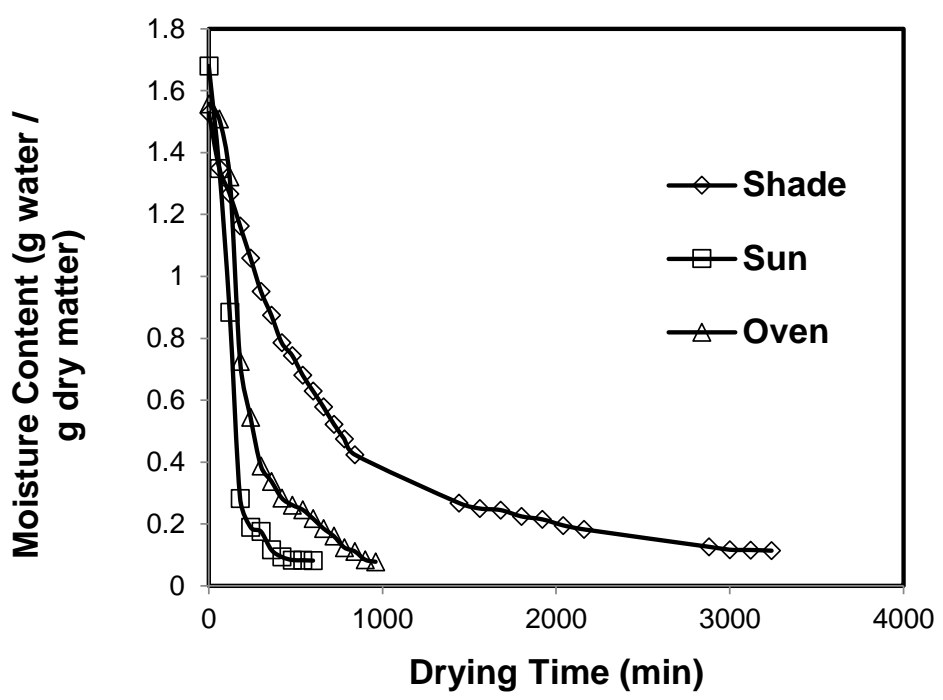

Fig. 1. Drying curves for jackfruit leaves and data given are the mean values of three replications

The predicted data by the Newton model and experimental data moisture ratios versus drying time for jackfruit leaves are shown in Fig. 2. The results showed that drying air temperature was an effective parameter for the drying of jackfruit leaves. Seven different drying models of MR were used to predict the moisture content as a function of drying time (Table 1).

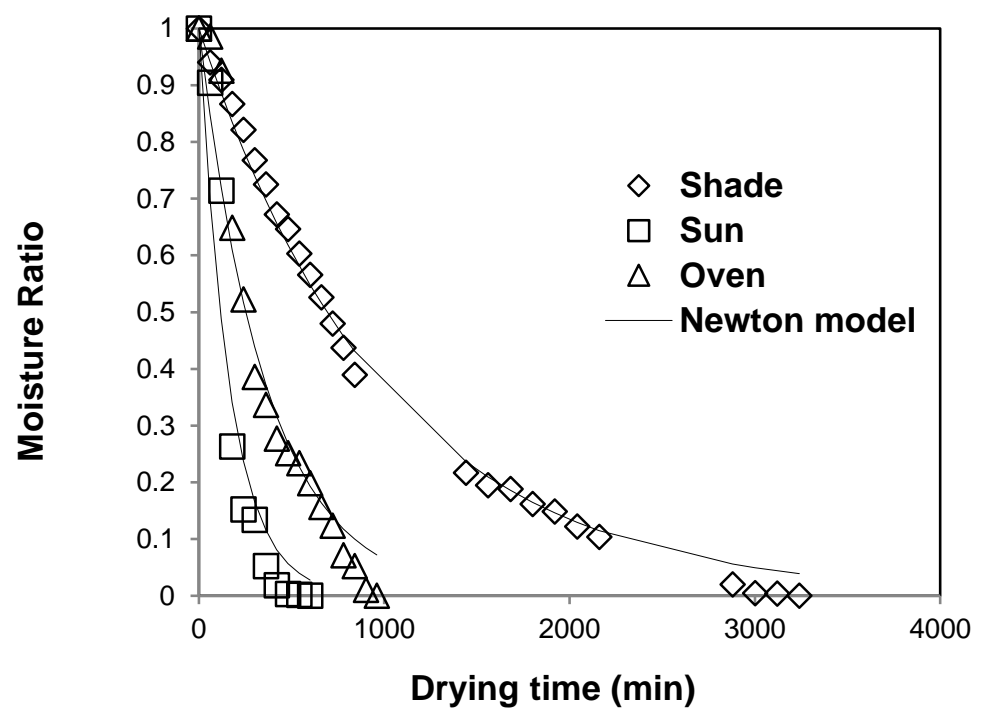

Fig. 2. Variation of moisture ratio of experiment and predicted by Newton model of various drying conditions for jackfruit leaves and data given are the mean values of three replications 
Table 3. Curve Fitting for Shade, Sun, and Oven Drying

\begin{tabular}{|c|c|c|c|c|c|c|}
\hline Model Name & Drying Condition & \multicolumn{2}{|r|}{ Constants } & $\mathrm{R}^{2}$ & RMSE & $x^{20}$ \\
\hline Newton* & $\begin{array}{l}\text { Shade } \\
\text { Sun } \\
\text { Oven }\end{array}$ & \multicolumn{2}{|r|}{$\begin{array}{l}\mathrm{k}=0.0010 \\
\mathrm{k}=0.0059 \\
\mathrm{k}=0.0027\end{array}$} & $\begin{array}{l}0.9948 \\
0.9999 \\
0.9999\end{array}$ & $\begin{array}{l}0.1676 \\
0.1002 \\
0.0974\end{array}$ & $\begin{array}{l}0.3480 \\
0.2450 \\
0.2208\end{array}$ \\
\hline Logarithmic & $\begin{array}{l}\text { Shade } \\
\text { Sun } \\
\text { Oven }\end{array}$ & \multicolumn{2}{|r|}{$\begin{array}{lll} & \mathrm{k}=0.0027 \\
09 & \mathrm{k}=0.0011 & \mathrm{c}=0.1206 \\
09 & \mathrm{k}=1.0000 & \mathrm{c}=0.3015 \\
40 & \mathrm{k}=1.0000 & \mathrm{c}=0.3014\end{array}$} & $\begin{array}{l}0.9460 \\
0.9963 \\
0.9998\end{array}$ & $\begin{array}{l}0.1515 \\
0.0644 \\
0.0974\end{array}$ & $\begin{array}{l}0.3147 \\
0.1459 \\
0.2208\end{array}$ \\
\hline Verma & $\begin{array}{l}\text { Shade } \\
\text { Sun } \\
\text { Oven }\end{array}$ & $\begin{array}{l}\mathrm{a}=1.0700 \\
\mathrm{a}=1.6497 \\
\mathrm{a}=1.2200\end{array}$ & $\begin{array}{ll}\mathrm{k}=0.0012 & \mathrm{~g}=1.3309 \\
\mathrm{k}=0.0089 & \mathrm{~g}=0.7500 \\
\mathrm{k}=0.0033 & \mathrm{~g}=0.5000\end{array}$ & $\begin{array}{l}0.9906 \\
0.9772 \\
0.9847\end{array}$ & $\begin{array}{l}0.1662 \\
0.0619 \\
0.0945\end{array}$ & $\begin{array}{l}0.3451 \\
0.1404 \\
0.2141\end{array}$ \\
\hline Two Term & $\begin{array}{l}\text { Shade } \\
\text { Sun } \\
\text { Oven }\end{array}$ & $\begin{array}{l}a=0.5510 \\
a=0.5000 \\
a=0.5500\end{array}$ & $\begin{array}{l}\mathrm{k}_{0}=0.0010 \quad \mathrm{~b}=0.4700 \\
\mathrm{k}_{1}=0.0012 \\
\mathrm{k}_{0}=0.0085 \quad \mathrm{~b}=0.5799 \\
\mathrm{k}_{1}=0.0033 \\
\mathrm{k}_{0}=0.0030 \\
\mathrm{k}_{1}=0.0033\end{array}$ & $\begin{array}{l}0.9934 \\
0.8718 \\
0.9692\end{array}$ & $\begin{array}{l}0.1671 \\
0.0493 \\
0.0915\end{array}$ & $\begin{array}{l}0.1431 \\
0.1117 \\
0.2074\end{array}$ \\
\hline Henderson and Pabis & $\begin{array}{l}\text { Shade } \\
\text { Sun } \\
\text { Oven }\end{array}$ & \multicolumn{2}{|c|}{$\begin{array}{ll}\mathrm{a}=1.0490 & \mathrm{k}=0.0010 \\
\mathrm{a}=1.0987 & \mathrm{k}=0.0059 \\
\mathrm{a}=1.2000 & \mathrm{k}=0.0034\end{array}$} & $\begin{array}{l}0.9935 \\
0.9292 \\
0.9620 \\
\end{array}$ & $\begin{array}{l}0.1600 \\
0.0560 \\
0.0901\end{array}$ & $\begin{array}{l}0.3471 \\
0.1269 \\
0.2043\end{array}$ \\
\hline Midilli & $\begin{array}{l}\text { Shade } \\
\text { Sun } \\
\text { Oven }\end{array}$ & \multicolumn{2}{|c|}{$\begin{array}{llll}9359 & k=0.0018 & n=0.9040 & b=0 \\
9965 & k=0.0060 & n=0.9990 & b=0 \\
0997 & k=0.0031 & n=0.9990 & b=0\end{array}$} & $\begin{array}{l}0.9681 \\
0.9168 \\
0.9687\end{array}$ & $\begin{array}{l}0.1587 \\
0.0545 \\
0.0914 \\
\end{array}$ & $\begin{array}{l}0.0684 \\
0.1236 \\
0.2073 \\
\end{array}$ \\
\hline Page & $\begin{array}{l}\text { Shade } \\
\text { Sun } \\
\text { Oven }\end{array}$ & \multicolumn{2}{|c|}{$\begin{array}{ll}\mathrm{k}=0.0010 & \mathrm{n}=1.0010 \\
\mathrm{k}=0.0035 & \mathrm{n}=1.0999 \\
\mathrm{k}=0.0025 & \mathrm{n}=1.0249\end{array}$} & $\begin{array}{l}0.9945 \\
0.9357 \\
0.9563\end{array}$ & $\begin{array}{l}0.1677 \\
0.0567 \\
0.0890\end{array}$ & $\begin{array}{l}0.3481 \\
0.1287 \\
0.2019 \\
\end{array}$ \\
\hline
\end{tabular}


The statistical analyses of curve fitting coefficient determination $\left(\mathrm{R}^{2}\right)$, reduced root mean square error (RMSE), and reduced chi-square, characterized for jackfruit leaves dried under shade, sun, and oven conditions are shown in Table 3. Newton, Logarithmic, and Verma models exhibited high values of $\mathrm{R}^{2}$ for all drying treatments ranging between 0.9460 and 0.9999 with slightly low RMSE values ranging from 0.0644 to 0.1676 .

\section{Effective Diffusivity}

The effective diffusivity $\left(D_{\text {eff }}\right)$ values $\left(\mathrm{m}^{2} / \mathrm{s}\right)$ of dried jackfruit leaves for shade, sun, and oven drying treatments were $2.9203 \times 10^{-10}, 6.8141 \times 10^{-10}$, and $6.5707 \times 10^{-10}$, respectively. Sun drying possessed the highest $D_{\text {eff }}$ values, which were approximately 2.3 fold than that of shade drying. For shade and sun drying, it was expected that $D_{\text {eff }}$ values increased with the increase in temperature. The $D_{\text {eff }}$ value for the sun drying was 1.04 fold greater than that for oven, which revealed that the process of open sun drying had better mass transfer efficiency than that of oven drying treatment studied. This can be associated with the free air circulation during open drying process. In general, $D_{\text {eff }}$ values fall within the range of $10^{-11}$ to $10^{-9}$ for dried food materials (Arslan and Özcan 2010).

\section{Colour}

Drying treatments had a significant effect on the color changes of jackfruit leaves. Therefore, colour assessment is another parameter that was observed during the drying of leaves. The colour measurement of dried jackfruit leaves revealed that the $L^{*}$ value of shade drying treatment was the highest among all dried leaves (15.8), followed by oven drying (13.4), while sun drying revealed the lowest $L^{*}$ value (11.1) among dried treatments $(\mathrm{P}<0.05)$. Exposure to direct sunlight is the most effective factor in color damage during drying (Rahimmalek and Goli 2013). Similar results were obtained for $b^{*}$ values. Sun drying treatment showed the highest $b^{*}$ value (39.5) in comparison to others. For $a^{*}$ value (greenness), shade drying treatment had the highest value (more negative), while sun drying showed the most discoloration of green pigment. Sun drying caused a more significant increment of $a^{*}$ values than the other treatments, which suggested that the degradation of green color (Fig. 3) in the final product occurred in a greater ratio. This could be due to the loss of chlorophyll content that is responsible for the green color of plant leaf and enzymatic browning.

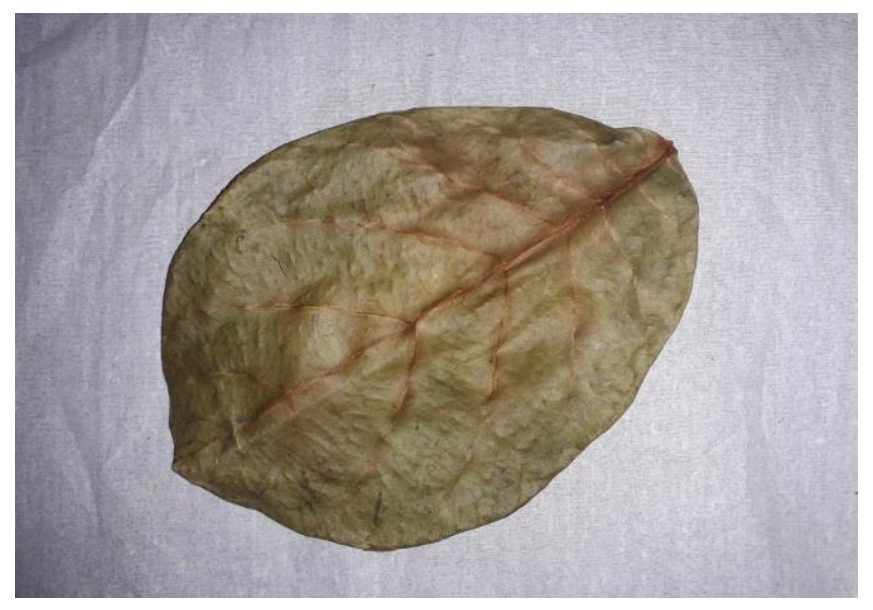

Fig. 3. Degradation of green colour of sun-dried jackfruit leaf 
The degradation of chlorophyll could be due to the chemical nature of pigments that are responsible for the green colour in leaves. Plant leaves containing chlorophyll A and B will degrade to pheophytin A and B, respectively when exposed to the heat. During the process of exposure to heat, pheophytin is produced when chlorophyll containing magnesium was replaced by two hydrogen atoms in the presence of mild acids (Izli et al. 2017; Roshanak et al. 2016). The possibility of discolouration of green colour was expected to occur in sun-dried jackfruit leaves. Therefore, sun drying is known to be the least desirable for the final dried product. Overall, sun and shade treatments were considered the least and the most desirable drying methods, respectively, regarding the final colour of jackfruit leaves.

\section{Total Phenolic Content and Total Flavonoid Content}

The impacts of drying treatment on TPC and TFC are shown in Fig. 4. It was found that there was a significant increase in total phenolic content and total flavonoid content observed over the extraction drying treatments (SD, SN, and OV), and the total phenolic content and total flavonoid content reached maximum values around $195.05 \mathrm{mg}$ GAE/g and $11.02 \mathrm{mg} \mathrm{AE} / \mathrm{g}$ of jackfruit leave extracts, respectively, both dried in the oven. At different drying treatments, there were significant percentage increments for the OV80 that were 1.33 and 1.28 fold higher than that for shade and sun. The TFC observed the highest value of $11.02 \mathrm{mg} \mathrm{AE} / \mathrm{g}$ of jackfruit leave extracts dried in the oven, 1.48 fold and 1.20 fold significantly greater than the shade and sun, respectively.

The increase in TPC and TFC as affected by drying treatment could be due to the liberation of the cell constituents from the plant cell that may accelerate the movement of bound phenolic and flavonoid compounds due to the thermal treatment as the heat exerts adjustments to the plant tissue microstructure, thus rupturing the structure of cell integrity, thereby allowing migration of phenolic compounds from the plant cells (Chua et al. 2019b). The longer time required for shade drying and the exposure to UV under open sun may affect the sensitive phytochemical compounds toward breakdown under various factors of chemical reaction comprising of light, oxygen, and enzymes (MartinezLas Heras et al. 2014).

The effect of ethanol concentrations on the extraction of TPC and TFC in jackfruit leaves extracts are shown in Fig. 4. At different ratios of ethanol/water from $0 \%$ to $80 \%$ for the same drying treatment, results showed an increase in TPC and TFC values. There were significant increments at $80 \% \mathrm{E} / \mathrm{W}$, which possessed 2.67 fold and 5.68 fold higher values than water extraction for TPC and TFC assays. However, when ethanol concentration reached $100 \%(\mathrm{v} / \mathrm{v})$, the TPC and TFC values in jackfruit leave extracts decreased. The decline in values for the jackfruit leaves extract could be due to some lipid components that were also extracted, which may hinder the extraction of phenolic compounds in jackfruit leaves extracts. While the extraction with water alone may not allow the optimum extraction of phenolic and flavonoid compounds, water extraction exhibited the lowest amount of phenolic and flavonoid content in this result. However, the addition of certain percentage of ethanol into water could improve extraction efficiency as the solubility of carbohydrates and proteins in ethanol is higher than water (Alara et al. 2018). In this study, it showed that JL contained more semi-polar constituents than polar ones. 

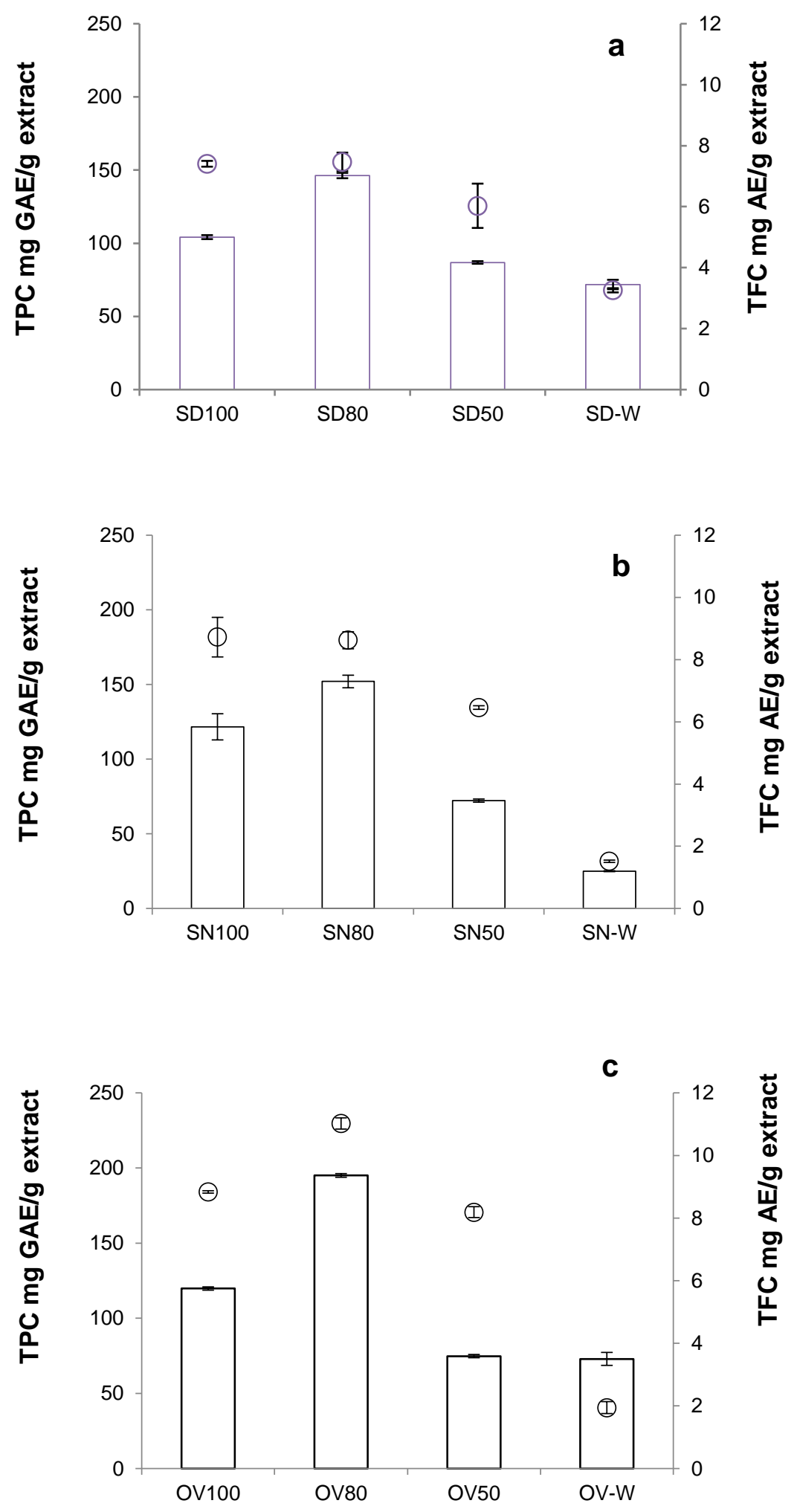

Fig. 4. Effect of different drying treatments and ethanol/water ratios on total phenolic content and TFC of jackfruit ( $A$. heterophyllus) leaves extract: a: shade, b: sun, and c: oven; Legend:

- - TPC, - ० - TFC 


\section{Antioxidant Activities}

The impact of drying treatment on DPPH and FRAP is shown in Fig. 5. Based on Fig. 5(a to c), the results showed that the free radical scavenging activities (DPPH) and ferric reducing absorption power (FRAP) of jackfruit leaves extract were highest attained in oven treatment, with values of $90.1 \%$ and $1043.80 \mu \mathrm{M} \mathrm{TE} / \mathrm{g} \mathrm{EW}$, respectively. Meanwhile, samples dried by shade drying and sun drying showed the lowest DPPH and FRAP, which were $58.8 \%$ and $197.50 \mu \mathrm{M}$ TE/g EW, respectively.

Temperature and drying time were considered as two crucial parameters for interpreting sample extract yield variation when employing different techniques to analyze (Hamrouni-Sellami et al. 2013). Higher reducing capacity of an extract serves as an indicator of the ability of its higher potential antioxidant activity. The oven drying treatment at $40{ }^{\circ} \mathrm{C}$ may still be able to preserve the heat sensitive bioactive compound present in JL extract. In previous studies, the antioxidant activities and polyphenol contents in heat-treated various herb leaves increased, indicating that phenolic compounds at a partial state of oxidation are exposed to oxygen and may exert a high antioxidant activity (Yi and Wetzstein 2011; Chua et al. 2019a).

However, under shade treatment, the lengthy process of exposure to oxygen may imply a greater exposure of the material to enzymatic and oxidation reactions, which thus accelerate the degradation of active compounds. Meanwhile, the antioxidant potential in sun treatment was lower than the oven treatment, which could be due to the direct exposure to sunlight that might degrade the compounds. Evidently, the shorter time in sun treatment did not compensate the deterioration of the antioxidant compounds that could be beneficial to human health (Martinez-Las Heras et al. 2014; Barimah et al. 2017).

At different solvent ratios, it was found that extraction using $80 \%$ ethanol/water (SD80, SN80, and OV80) exhibited significantly higher $(\mathrm{P}<0.05)$ FRAP $(1043.84 \mu \mathrm{M}$ TE/g extract weight) and DPPH (90\% scavenging effect) values compared to other ratios. The OV80 were found to possess 2.85 fold (FRAP value) and 1.43 fold (free radical scavenging effect) higher jackfruit leaves extract than that of water extraction (365.72 $\mu \mathrm{M} \mathrm{TE} / \mathrm{g}$ extract weight and $64.7 \%$, respectively). This could be explained by the tendency of phenols to dissolve in a wide range of mixtures of aqueous ethanol compared to water extraction alone. Solvent polarity played an important role in the extractability and solubility of bioactive compounds from plant materials. Several studies have been reported on extracting bioactive compounds using different single solvent, solvent mixtures, and solvent ratios (Pin et al. 2010; Dube et al. 2017). Alothman et al. (2009) reported the highest antioxidant capacities of FRAP at $70 \%$ ethanol-water mixtures by increasing the effectiveness of the swelling power of plants with the presence of water and providing high surface area of solute-solvent contact. The addition of water will lower the mixture viscosity and thus will ameliorate the mass transfer of extract (Hemwimol et al. 2006).

\section{Correlation of Total Phenolic Contents and Their Antioxidant Activities}

It was demonstrated that SD80, SN80, and OV80 exhibited the highest TPC and TFC values compared to other ethanol aqueous compositions. The FRAP and DPPH assays showed the same orientations. In all treatments studied, the phenolic content and its related antioxidant activities exhibited high coefficient of determination $\left(\mathrm{R}^{2}\right)$ values at 0.9441 and 0.6700 , and were significant at $\mathrm{P}<0.05$. 

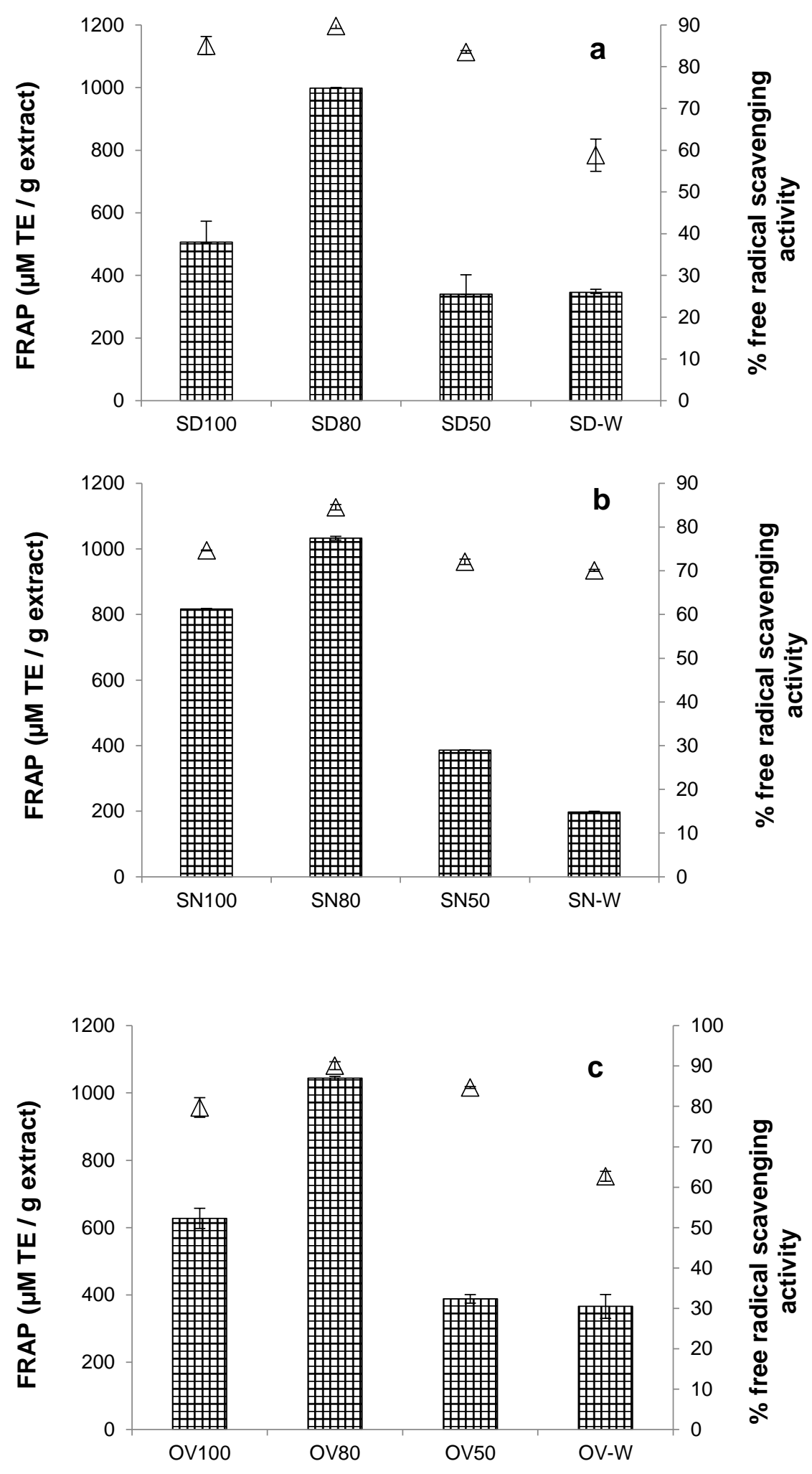

Fig. 5. Effect of different drying treatments and ethanol/water ratios on FRAP and DPPH of

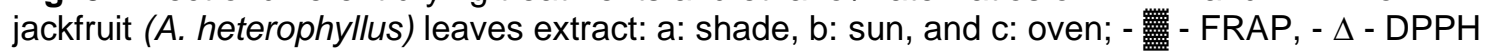


In accordance with TPC investigated, i.e., the highest content (80\% ethanol/water) demonstrated the highest in antioxidant activities in FRAP assay than any other compositions. However, as this correlation was inverted in the latter assay (DPPH), it was suggested that other constituents (e.g., non-phenolics) could be attributed to the antioxidant ability by donating hydrogen atom of $A$. heterophyllus leaves extract (Catarino et al. 2018).

Meanwhile, the correlation between total flavonoid contents (TFC) and its associated antioxidant activities (FRAP and DPPH) yielded $\mathrm{R}^{2}$ values of 0.7857 and 0.7472 , respectively. These correlations exerted their different mechanisms and ability to reduce certain free radicals to form a stable compound and metal ions chelation (Maisarah et al. 2013). The mechanism of FRAP and DPPH employed the antioxidant ability to diminish certain radicals (ferric iron and DPPH radical). Another significant correlation between TPC and antioxidant capacity of plant extracts (FRAP and DPPH values) was attained. Based on these correlations, it can be assumed that the phenolic compounds were predominant in contributing to the antioxidant activities of these ethanolic compositions. Different antioxidant activities can be attributed to different mechanism of action either by electron transfer (ET) or hydrogen atom transfer (HAT) (Mustafa et al. 2016). Since FRAP values of SD80, SN80 and OV80 extracts were significantly higher $(\mathrm{P}<0.05)$ than that scavenging activity, sample may act as HAT to stabilize lipid oxidation.

\section{Artocarpin and Volatile Compounds of Jackfruit Leaves Extract}

The artocarpin, squalene, and $\beta$-sitosterol content of shade, sun, and oven-dried treatments at $80 \%$ ethanol/water ratio (highest values of antioxidant properties) are given in Table 4. All crude samples assayed contained $4.71 \pm 0.59 \mathrm{mg} / \mathrm{g}$ extract (SD80), $2.53 \pm$ $0.29 \mathrm{mg} / \mathrm{g}$ extract (SN80), and $8.35 \pm 1.78 \mathrm{mg} / \mathrm{g}$ extract (OV80), where OV80 showed significantly higher $(\mathrm{P}<0.05)$ artocarpin content compared to other drying treatments. Meanwhile, the same results for volatile organic compounds were observed for squalene and $\beta$-sitosterol. Squalene content of OV80 $(1.47 \mathrm{mg} / \mathrm{g})$ was found higher than other drying treatments. However, the $\beta$-sitosterol content of SD80 and OV80 was found not statistically significant. Sun drying showed the lowest values of both volatile compounds. In this study, oven drying at low temperature with $80 \%$ ethanol/water ratio led to the bound phenolic and flavonoid contents being released from the plant matrix and recovered from the thick mass extract during the extraction. A previous study also reported that oven drying at low temperature is suitable in preserving the antioxidant values among other dried leave methods such as shade and sun drying (Babu et al. 2018). As far as the authors know, there is no report on profiling to detect the presence of bioactive compounds of interest in the effect of different drying methods and ethanol compositions on quality attributes on jackfruit leaves extract. 
Table 4. Artocarpin, Squalene, and $\beta$-sitosterol Content in JL Extract

\begin{tabular}{|c|c|c|c|}
\hline \multirow{2}{*}{ Sample } & \multicolumn{3}{|c|}{ Content $(\mathrm{mg} / \mathrm{g})$} \\
\cline { 2 - 4 } & Artocarpin & Squalene & $\beta$-sitosterol \\
\hline SD80 & $4.71 \pm 0.59^{\mathrm{b}}$ & $1.12 \pm 0.09^{\mathrm{b}}$ & $0.32 \pm 0.02^{\mathrm{a}}$ \\
\hline SN80 & $2.53 \pm 0.29^{\mathrm{c}}$ & $0.55 \pm 0.06^{\mathrm{c}}$ & $0.11 \pm 0.01^{\mathrm{b}}$ \\
\hline OV80 & $8.35 \pm 1.78^{\mathrm{a}}$ & $1.47 \pm 0.01^{\mathrm{a}}$ & $0.28 \pm 0.02^{\mathrm{a}}$ \\
\hline $\begin{array}{l}\text { Note: abc Significant difference }(\mathrm{p}<0.05) \text { of one sample over the other(s) if values in the same } \\
\text { column carry different superscript }\end{array}$ \\
\hline
\end{tabular}

\section{CONCLUSIONS}

1. Different drying treatments and ethanol/water ratios on extraction resulted in differences in color, total phenolic content (TPC), total flavonoid content (TFC), and the antioxidant activities, which were investigated individually.

2. Newton model proved to be the best fit model for describing drying behavior of drying treatments of jackfruit leaves (JL). The moisture effective diffusivity calculated from the second Fick's law was within the range $2.920 \times 10^{-10}$ to $6.814 \times$ $10^{-10} \mathrm{~m}^{2} / \mathrm{s}$ over the temperature range studied.

3. Oven-drying with $80 \%$ ethanol/water (OV80) ratio provided highest antioxidant properties (phenolic and flavonoid contents as well as antioxidant activities) and acceptable color properties better than the conventional drying treatments.

4. Degradation in green colour can be considered as an index for loss of quality in product. However, minimal colour losses in oven-dried leaves do not have an impact on the antioxidant performance in this study. Overall, oven drying is worth to be considered for drying jackfruit leaves.

\section{ACKNOWLEDGMENTS}

This study was supported by Universiti Putra Malaysia of Research, Grant No. 9524900 .

\section{REFERENCES CITED}

Alara, O. R., Abdurahman, N. H., Kholijah, S., and Mudalip, A. (2018). "Mathematical modeling of thin layer drying using open sun and shade of Vernonia amygdalina leaves," Agriculture and Natural Resources 52(1), 53-58. DOI: 10.1016/j.anres.2018.05.013

Alothman, M., Bhat, R., and Karim, A. A. (2009). "Antioxidant capacity and phenolic content of selected tropical fruits from Malaysia, extracted with different solvents," Food Chemistry 115(3), 785-788. DOI: 10.1016/j.foodchem.2008.12.005

Arslan, D., and Özcan, M. M. (2010). "Study the effect of sun, oven and microwave drying on quality of onion slices," LWT - Food Science and Technology 43(7), 11211127. DOI: $10.1016 / j .1 w t .2010 .02 .019$ 
Bruschweiler, H., and Dieffenbacher, A. (1991). "Determination of mono- and diglycerides by capillary gas chromatography," Pure \& Applied Chemistry 63(8), 1153-1162. DOI: 10.5650/jos1956.41.166

Babu, A. K., Kumaresan, G., Aroul, V. A., and Velraj, R. (2018). "Review of leaf drying: Mechanism and influencing parameters, drying methods, nutrient preservation, and mathematical models," Renewable and Sustainable Energy Reviews 90, 536-556. DOI: 10.1016/j.rser.2018.04.002

Baliga, M. S., Shivashankara, A. R., Haniadka, R., Dsouza, J., and Bhat, H. P. (2011). "Phytochemistry, nutritional and pharmacological properties of Artocarpus heterophyllus Lam (jackfruit): A review," Food Research International 44(7), 18001811. DOI: 10.1016/j.foodres.2011.02.035

Barimah, J., Yanney, P., Laryea, D., and Quarcoo, C. (2017). "Effect of drying methods on phytochemicals, antioxidant activity and total phenolic content of dandelion leaves," American Journal of Food and Nutrition 5(4), 136-141. DOI: 10.12691/ajfn5-4-4

Catarino, M. D., Silva, A. M. S., Saraiva, S. C., Sobral, A. J. F. N., and Cardoso, S. M. (2018). "Characterization of phenolic constituents and evaluation of antioxidant properties of leaves and stems of Eriocephalus africanus," Arabian Journal of Chemistry 11(1), 62-69. DOI: 10.1016/j.arabjc.2015.04.018

Chua, L. Y. W., Chua, B. L., Figiel, A., Chong, C. H., Wojdyło, A., Szumny, A., and Łyczko, J. (2019a). "Drying of Phyla nodiflora leaves: Antioxidant activity, volatile and phytosterol content, energy consumption, and quality studies," Processes 7(4), Article number 210. DOI: 10.3390/pr7040210

Chua, L. Y. W., Chua, B. L., Figiel, A., Chong, C. H., Wojdyło, A., Szumny, A., and Choong, T. S. Y. (2019b). "Antioxidant activity, and volatile and phytosterol contents of strobilanthes crispus dehydrated using conventional and vacuum microwave drying methods," Molecules 24(7), 1-21. DOI: 10.3390/molecules24071397

Donkor, A. M., Nashirudeen, Y., and Suurbaar, J. (2016). "Stability evaluation and degradation kinetics of rutin in ficus pumila leaves formulated with oil extracted from moringa oleifera seeds," Journal of Analytical and Pharmaceutical Research 3(2), 17. DOI: 10.15406/japlr.2016.03.00051

Doymaz, I., and Kipcak, A. S. (2018). "Effect of pretreatment and air temperature on the drying time of cherry tomato," Journal of Thermal Engineering 4(1), 1648-1655.

DOI: 10.18186/journal-of-thermal-engineering.364489

Dube, P., Meyer, S., and Marnewick, J. L. (2017). "Antimicrobial and antioxidant activities of different solvent extracts from fermented and green honeybush (Cyclopia intermedia) plant material," South African Journal of Botany 110, 184-193. DOI: 10.1016/j.sajb.2016.10.010

Hamrouni-Sellami, I., Rahali, F. Z., Rebey, I. B., Bourgou, S., Limam, F., and Marzouk, B. (2013). "Total phenolics, flavonoids, and antioxidant activity of sage (Salvia officinalis L.) plants as affected by different drying methods," Food Bioprocess Technology 6, 806-817. DOI: 10.1007/s11947-012-0877-7

Hemwimol, S., Pavasant, P., and Shotipruk, A. (2006). "Ultrasound-assisted extraction of anthraquinones from roots of Morinda citrifolia," Ultrasonics Sonochemistry 13(6), 543-548. DOI: 10.1016/j.ultsonch.2005.09.009

Izli, N., Izli, G., and Taskin, O. (2017). "Drying kinetics, colour, total phenolic content and antioxidant capacity properties of kiwi dried by different methods," Journal of 
Food Measurement and Characterization 11(1), 64-74. DOI: 10.1007/s11694-0169372-6

Jagtap, U. B., and Bapat, V. A. (2010). "Artocarpus: A review of its traditional uses, phytochemistry and pharmacology," Journal of Ethnopharmacology 129(4), 142 166. DOI: $10.1016 /$ j.jep.2010.03.031

Jain, D., and Tiwari, G. N. (2003). "Thermal aspects of open sun drying of various crops," Energy 28(1), 37-54. DOI: 10.1016/S0360-5442(02)00084-1

Kumar, A., and Tiwari, G. N. (2007). "Effect of mass on convective mass transfer coefficient during open sun and greenhouse drying of onion flakes," Journal of Food Engineering 79(4), 1337-1350. DOI: 10.1016/j.jfoodeng.2006.04.026

Liu, L., Sun, Y., Laura, T., Liang, X., Ye, H., and Zeng, X. (2009). "Determination of polyphenolic content and antioxidant activity of kudingcha made from Ilex kudingcha C. J. Tseng," Food Chemistry 112(1), 35-41. DOI: 10.1016/j.foodchem.2008.05.038

Loizzo, M. R., Tundis, R., Chandrika, U. G., Abeysekera, A. M., Menichini, F., and Frega, N. G. (2010). "Antioxidant and antibacterial activities on foodborne pathogens of Artocarpus heterophyllus Lam. (Moraceae) leaves extracts," Journal of Food Science 75(5), 291-295. DOI: 10.1111/j.1750-3841.2010.01614.x

Maisarah, M. H., Noriham, A., and Zainon, M. N. (2013). "Quantification of polyphenolic acids and antioxidant capacity of palm puree from different tenera breeds of Elaeis Guineensis," International Journal of Bioscience, Biochemistry and Bioinformatics 3(4), 349-353.

Martinez-Las Heras, R., Heredia, A., Castello, M. L., and Andre, A. (2014). "Influence of drying method and extraction variables on the antioxidant properties of persimmon leaves," Food Bioscience 6, 1-8. DOI: 10.1016/j.fbio.2014.01.002

Mustafa, H. M., Abdullah, N., and Noor, Z. M. (2016). "Quantitative analysis of hydrophilic and lipophilic antioxidant components in palm puree," in: Regional Conference on Science, Technology and Social Sciences (RCSTSS 2014): Science and Technology (RCSTSS 2014), N. Yacob, M. Mohamed, and M. Megat Hanafiah (ed.), Springer, Singapore, pp. 147-156.

Ojwang, R. A., Muge, E. K., Mbatia, B., Mwanza, B., and Ogoyi, D. O. (2017). "Comparative analysis of phytochemical composition and antioxidant activities of methanolic extracts of leaves, roots and bark of jackfruit (Artocapus heterophyllus) from selected regions in Kenya and Uganda," Journal of Advances in Biology and Biotechnology 16(1), 1-13. DOI: 10.9734/JABB/2017/37355

Perva-Uzunalic, A., Otto, F., and Gru, S. (2006). "Extraction of active ingredients from green tea (Camellia sinensis): Extraction efficiency of major catechins and caffeine," Food Chemistry 96(4), 597-605. DOI: 10.1016/j.foodchem.2005.03.015

Pin, K. Y., Chuah, A. L., Rashih, A. A., Mazura, M. P., Fadzureena, J., Vimala, S., and Rasadah, M. A. (2010). "Antioxidant and anti-inflammatory activities of extracts of betel leaves (Piper betle) from solvents with different polarities," Journal of Tropical Forest Science 22(4), 448-455. DOI: 10.2307/23616901

Prakash, O., Srivastava, R., Kumar, R., Mishra, S., and Srivastavam, S. (2017). "Preliminary pharmacognostic and phytochemical studies on leaves of Artocarpus heterophyllus," International Journal of Natural Products and Marine Biology 1(1), 35-40.

Prasad, J. A. (2009). "Convective heat transfer in herb and spices during open sundrying," International Journal of Food Science + Technology 44(4), 657-665. DOI: $10.1111 /$ j.1365-2621.2006.01269.x 
Rahimmalek, M., and Goli, S. A. H. (2013). "Evaluation of six drying treatments with respect to essential oil yield, composition and color characteristics of Thymys daenensis subsp. Daenensis. celak leaves," Industrial Crops and Products 42, 613619. DOI: 10.1016/j.indcrop.2012.06.012

Roshanak, S., Rahimmalek, M., and Goli, S. A. H. (2016). "Evaluation of seven different drying treatments in respect to total flavonoid, phenolic, vitamin $\mathrm{C}$ content, chlorophyll, antioxidant activity and color of green tea (Camellia sinensis or $C$. assamica) leaves," Food Science Technology 53(1), 721-729. DOI: 10.1007/s13197015-2030-X

Septama, A. W., and Panichayupakaranant, P. (2016). "Simultaneous HPLC analysis of three flavonoids in the extracts of artocarpus heterophyllus heartwoods," Natural Product Sciences 22(2), 77-81. DOI: 10.20307/nps.2016.22.2.77

Sodha, M. S., Dang, A., Bansal, P. K., and Sharman, S. B. (1985). "An analytical and experimental study of open sun drying and a cabinet tyre drier," Energy Conversion and Management 25(3), 263-271. DOI: 10.1016/0196-8904(85)90042-1

Tellez, C. M., Figueroa, P. I., Tellez, C. B., Vidana, E. C. L., and Ortiz, A. L. (2018). "Solar drying of Stevia (Rebaudiana bertoni) leaves using direct and indirect technologies," Solar Energy 159, 898-907. DOI: 10.1016/j.solener.2017.11.031

Yamaguchi, T., Takamura, H., Matoba, T., and Terao, J. (1998). "HPLC method for evaluation of the free radical-scavenging activity of foods by using 1, 1-diphenyl-2picrylhydrazyl," Bioscience, Biotechnology, and Biochemistry 62(6), 1201-1204. DOI: $10.1271 / \mathrm{bbb} .62 .1201$

Yi, W., and Wetzstein, H. Y. (2011). "Effects of drying and extraction conditions on the biochemical activity of selected herbs," HortSciencec 46(1), 70-73. DOI: 10.21273/HORTSCI.46.1.70

Zheng, Z. P., Xu, Y., Qin, C., Zhang, S., Gu, X., Lin, Y., Xie, G., Wang, M., and Chen, J. (2014). "Characterization of antiproliferative activity constituents from Artocarpus heterophyllus," Journal of Agricultural and Food Chemistry 62(24), 5519-5527. DOI: $10.1021 / j f 500159 z$

Article submitted: February 18, 2020; Peer review completed: May 3, 2020; Revised version received and accepted: May 12, 2020; Published: May 15, 2020.

DOI: $10.15376 /$ biores. 15.3.5122-5140 